\title{
ON THE INFLUENCE OF GLOBAL WARMING ON ATLANTIC HURRICANE FREQUENCY
}

\author{
S. R. Hosseini ${ }^{1, *}$, M. Scaioni ${ }^{2}$, M. Marani ${ }^{3}$ \\ ${ }^{1}$ Politecnico di Milano, Department of Civil and Environmental Engineering (DICA) \\ piazza L. da Vinci 32, 20133 Milano, Italy - email: seyedreza.hosseini@polimi.it \\ ${ }^{2}$ Politecnico di Milano, Department of Architecture, Built Environment and Construction Engineering (DABC) \\ via Ponzio 31, 20133 Milano, Italy - email: marco.scaioni@polimi.it \\ ${ }^{3}$ Università degli studi di Padova, Department of Civil, Environmental and Architectural Engineering \\ via Loredan, 20, 35131 Padova, Italy - email: marco.marani@unipd.it
}

Commission III, WG III/9

KEYWORDS: Atlantic Ocean, Global Warming, Hurricanes, Hydrosphere, Metastatistical Analysis

\begin{abstract}
:
In this paper, the possible connection between the frequency of Atlantic hurricanes to the climate change, mainly the variation in the Atlantic Ocean surface temperature has been investigated. The correlation between the observed hurricane frequency for different categories of hurricane's intensity and Sea Surface Temperature (SST) has been examined over the Atlantic Tropical Cyclogenesis Regions (ACR). The results suggest that in general, the frequency of hurricanes have a high correlation with SST. In particular, the frequency of extreme hurricanes with Category 5 intensity has the highest correlation coefficient $(R=0.82)$. In overall, the analyses in this work demonstrates the influence of the climate change condition on the Atlantic hurricanes and suggest a strong correlation between the frequency of extreme hurricanes and SST in the ACR.
\end{abstract}

\section{INTRODUCTION}

Climate change and global warming are apparent across a wide range of observations. As a result, certain types of extreme weather events have become more frequent and intense, such as heat waves or floods and droughts in some regions. There is also an extended debate regarding the overall change in the activity of storms. In particular, variations in frequency and intensity of extreme storms, possibly due to the global warming, are at the focus of this scientific and societal debate (Knutson and Tuleya, 2004; Bender et al., 2010; Knutson et al., 2013, 2015; Kanada et al., 2017). Tropical Cyclones (TC) and hurricanes are among the most destructive kinds of storms in nature. They bring violent wind, flooding rains and cause significant economic and social disruptions. Hence, this phenomenon has a significant impact on human life and property. Consequently, the interest in characterizing the relationship between TCs and hurricanes with the global warming has increased in the recent years.

Several studies linked the formation of hurricanes to Sea Surface Temperature (SST) as one of its main drivers (Emanuel, 1991; Holland, 1997; Knutson and Tuleya, 2004; Bengtsson et al., 2007). Goni et al. (2002) suggested that those values of SST higher than $26^{\circ} \mathrm{C}$ or so are necessary for hurricane cyclogenesis. Also, hurricane intensification might have a statistical relationship with higher SST values (Fraza and Elsner, 2015) or be related to the location of high SST values (Sun et al., 2007). When all these topics are underlined, an assumption should be made, i.e., the most direct parameter controlling the influence of climate change conditions on hurricanes is SST. Thus a higher SST may imply a higher frequency or intensity of hurricanes (Mann and Emanuel, 2006; Webster, 2005). Therefore, understanding the relationship between the frequency of hurricanes with different intensities and SST plays a crucial role in storm risk assessment, emergency planning, and insurance industry.

The aim of this paper is initially to examine the observed frequency of Atlantic hurricanes for different categories of intensity. In a second stage, to investigate the possible correlation between frequency and warmer SST in each category of intensity separately.

\section{HURRICANES INTENSITY}

The intensity of hurricanes is defined according to SaffirSimpson Hurricane Wind Scale (SSHWS), see Schott et al. (2012). The SSHWS is a 1-5 categorization depending on the hurricane's Lifetime Maximum Intensity (LMI), see Table 1. The LMI refers to the highest hurricane's Maximum Sustained Wind (MSW) speed during the time from genesis to dissipation of each hurricane. And the MSW speed is a maximum 1-minute average wind speed which is measured within a hurricane at an elevation of $10 \mathrm{~m}$ a.s.l. and with an unobstructed exposure. In another word, the LMI is the value of MSW where the lifetime maximum occurs.

The procedure to estimate the hurricane's MSW is based on ship reports, satellite imagery using the Dvorak technique, aircraft reconnaissance, and land-based radar data. The Dvorak estimation technique was developed between 1969-1984 by Vernon Dvorak (Dvorak, 1975, 1984). This method is merely based on visible and infrared satellite images and is extensively used to estimate hurricane wind speed since 1970 (Velden et al., 2006). The aircraft reconnaissance measurements use dropsondes (reconnaissance device dropped from the aircraft), Stepped Frequency Microwave Radiometer (SFMR) and radar to remotely estimate wind speed, precipitation, temperature, pressure, and relative humidity. The aircraft reconnaissance is

Corresponding author 
costly, and only the National Hurricane Center (NHC) is routinely using this approach to directly measure Atlantic hurricane's wind speed and other properties.

The NHC best tracks are post-storm analyses of the measured wind speed, central pressure, position, and size of hurricanes and TCs at 6-hour interval. One MSW speed value is assigned to every cyclone at every best track time, i.e., every 6 hours. Therefore, to categorize hurricanes according to their intensities and study the related influence of global warming on the frequency of each category, the first step is to produce a hurricanes LMI data set for the required region and time period from the best tracks.

\begin{tabular}{|c|c|c|}
\hline $\begin{array}{l}\text { SSHWS } \\
\text { Category }\end{array}$ & $\begin{array}{c}\text { MSW } \\
\text { (knots) }\end{array}$ & $\begin{array}{l}\text { Description of possible } \\
\text { consequences }\end{array}$ \\
\hline 1 & $64-82$ & $\begin{array}{l}\text { Very dangerous winds will } \\
\text { produce some damage }\end{array}$ \\
\hline 2 & 83-95 & $\begin{array}{l}\text { Extremely dangerous winds will } \\
\text { cause extensive damage }\end{array}$ \\
\hline 3 & $96-112$ & Devastating damage will occur \\
\hline 4 & $113-136$ & Catastrophic damage will occur \\
\hline 5 & 137 & Catastrophic damage will occur \\
\hline
\end{tabular}

Table 1. The table of Saffir-Simpson hurricane wind scale (SSHWS. From the NHC, https://www.nhc.noaa.gov/ aboutsshws.php.

\section{ATLANTIC HURRICANE BEST TRACKS}

To produce the LMI data set, the revised Atlantic hurricane best tracks from the NHC, known as Atlantic HURDAT2 (Landsea et al., 2015) has been used. This historical database contains occurrences, and 6-hourly records of MSW speeds for all Atlantic storms. The procedure to estimate MSW speeds has been clarified in Section 2. The HURDAT2 database goes back to 1851. However, it is not complete and accurate for the entire period. The uncertainty estimates of HURDAT2 for the various period have been studied by different authors (Landsea et al., 2008, 2012, 2014; Hagen et al., 2012; Torn and Snyder, 2012; Landsea and Franklin, 2013). In general, new technologies affect the observations as our ability to detect the frequency, intensity, and size of tropical cyclones are always improving. Consequently, as one goes back further in time, besides the uncertainties, tropical cyclone frequencies may be underreported.

Several studies have been carried out to estimate the possible undercount of the occurrence of events (Chang and Guo, 2007; Mann et al., 2007; Vecchi and Knutson, 2008). In a most recent piece of literature (Vecchi and Knutson, 2011), a previously developed methodology by Vecchi and Knutson (2008) was applied to estimate missed hurricanes, either those entirely lost or those incorrectly considered as TCs. These methods allow for a more reliable estimation of the number of undercounting events before the beginning of satellite imagery. However, they are not intended to estimate the MSW of the undercounted hurricanes and the intensity of the missed events are not known. Recorded values of MSW in HURDAT2 best track database are given to the nearest 10 knots for the period 1851-1885, and to the nearest 5 knots in 1886-2016. With the intention of having a homogeneous data set, and to maximize the reliability of the data, only data recorded after 1886 have been used here. The hurricanes occurred in 2017 are not reported in the current version of HURDAT2 database (until the last update on $11^{\text {th }}$ April 2017). Therefore, the hurricane's MSW for this year are obtained from the NOAA's monthly Atlantic tropical report (https://www.nhc.noaa.gov/text/). These reported wind speeds from miles/hour to knots have converted and rounded to the nearest 5 knots to be compatible with the rest of data set. The reported MSW for 2017 hurricanes and their rounded values in knots are presented in Table 2.

\begin{tabular}{|l|l|c|c|c|}
\hline \multirow{2}{*}{$\begin{array}{c}\text { Hurricane } \\
\text { Name }\end{array}$} & \multicolumn{1}{|c|}{ Dates } & LMI \\
\cline { 3 - 5 } & & mph & knots & $\begin{array}{c}\text { nearest } \\
\text { 5 knots }\end{array}$ \\
\hline Franklin & 6-10 Aug & 85 & 73.86 & 75 \\
Gert & 13-17 Aug & 105 & 91.24 & 90 \\
Harvey & 17 Aug-1 Sept & 130 & 112.96 & 115 \\
Irma & 30 Aug-12 & 185 & 160.76 & 160 \\
Jose & Sept & 155 & 134.69 & 135 \\
Katia & 5-22 Sept & 105 & 91.24 & 90 \\
Lee & 5- 9 Sept & 115 & 99.93 & 100 \\
Maria & 15-30 Sept & 175 & 152.07 & 150 \\
Nate & 16-30 Sept & 92 & 80 & 80 \\
Ophelia & 4-9 Oct & 115 & 100 & 100 \\
\hline
\end{tabular}

Table 2. List of Atlantic hurricanes in 2017 stated in NOAA's monthly Atlantic tropical report.

The Atlantic tropical Cyclogenesis Regions (ACR) is a box bounded in latitude between $6^{\circ}-18^{\circ} \mathrm{N}$, and in longitude between $20^{\circ}-60^{\circ} \mathrm{W}$ (see Fig. 1). The literature (Emanuel, 2005; Santer et al., 2006) suggests that SST changes in this area are more correlated with hurricane's wind speed compared to the other regions. Therefore, in order to improve the analyses in this work, only those data for hurricanes in this area has been selected.

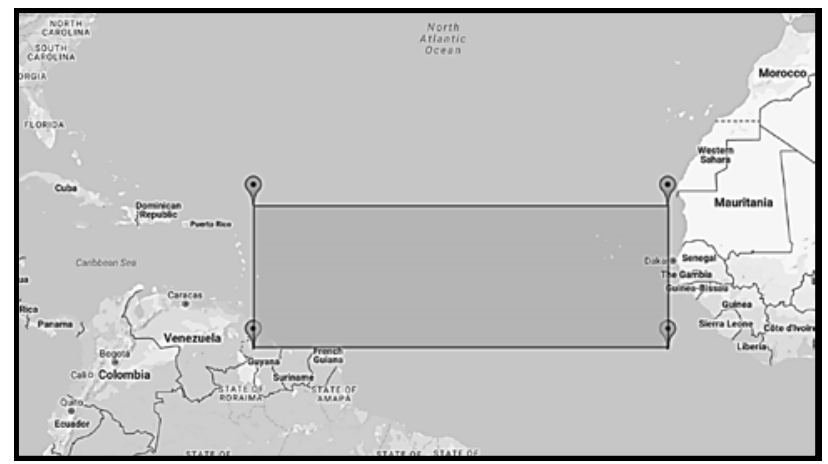

Figure 1. The Atlantic Tropical Cyclogenesis Region (ACR), bounded in latitude between $6^{\circ}-18^{\circ} \mathrm{N}$, and in longitude between $20^{\circ}-60^{\circ} \mathrm{W}$.

According to the SSHWS scale, between 1,566 recorded events in the ACR from 1886 to 2017, 734 storms have hurricane intensity, and 590 storms have TC intensity (Table 3). 


\begin{tabular}{|c|c|c|}
\hline Tropical cyclone & Wind speed (knots) & Counts \\
\hline All recorded & & 1566 \\
Tropical cyclone & $33-64$ & 590 \\
Hurricane & $>64$ & 734 \\
\hline
\end{tabular}

Table 3. Number of Atlantic hurricanes and TCs in HURDAT2.

\section{ATLANTIC YEARLY HURRICANE FREQUENCIES BASED ON LMI}

The yearly hurricane frequency is the number of hurricanes (TCs which reaches the minimum hurricane intensity) occurred in each year. The distribution of yearly hurricane frequency for the selected area and time period is presented in Figure 2.

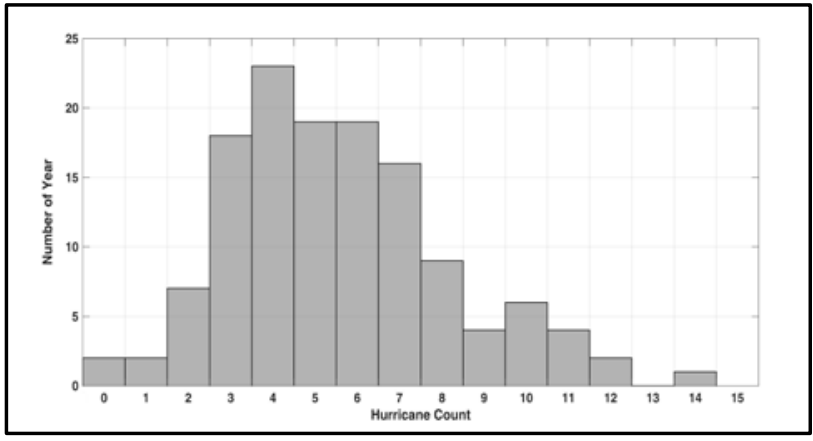

Figure 2. Distribution of yearly hurricane frequency in the ACR 1886 to 2017.

Figure 3, shows time series of occurred hurricanes. There are two years in the time series, 1907 and 1914, without any recorded hurricanes. In addition, the year 2005 has the highest number of events with 15 recorded hurricanes per year.

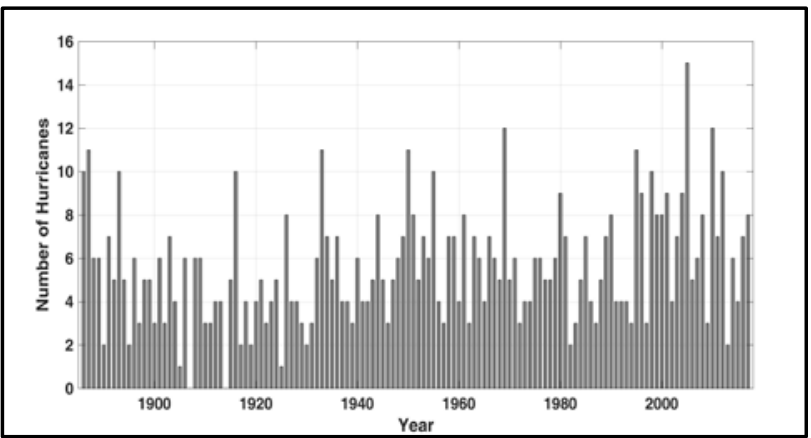

Figure 3. Time series of occurred hurricanes in the ACR from 1886 to 2017.

To produce the yearly hurricane frequency for each SSHWS category separately, initially, the LMI value for every recorded hurricane in the time series have been collected. The histogram of the produced LMI for the whole period are shown in Figure 4.

Then, the events are categorized according to SSHWS category and their LMI in every year. Table 4 shows the frequency and the rate of hurricanes in each category in the ACR for the whole 132-year period. As it is expected, the rate of hurricanes is decreasing by increasing their intensity. Category 5 intensity has the lowest rate of 0.25 compared to other categories.



Figure 4. Histogram of LMI for hurricanes in the ACR.

\begin{tabular}{|c|c|c|}
\hline Intensity & Frequency & Rate \\
\hline Cat. 1 & 271 & 2.05 \\
Cat. 2 & 182 & 1.38 \\
Cat. 3 & 136 & 1.03 \\
Cat. 4 & 112 & 0.85 \\
Cat. 5 & 33 & 0.25 \\
\hline
\end{tabular}

Table 4. The frequency and the rate of hurricanes for each SSHWS category in the ACR from 1886 to 2017.

Among the available hurricanes in the produced LMI database, there are few extreme events with a much higher recorded intensity. Table 5, shows the list of first, second and third most intense hurricanes in terms of LMI. Hurricane Allen in 1980, the most intense one, reaches the maximum intensity of 165 knots.

\begin{tabular}{|c|c|c|c|c|}
\hline \multirow{2}{*}{ Rank } & Hurricane's & \multirow{2}{*}{ Year } & \multicolumn{2}{|c|}{ LMI } \\
& name & & m/s \\
\hline First & Allen & 1980 & 165 & 84.88 \\
\hline \multirow{3}{*}{ Second } & $\begin{array}{c}\text { Labor Day } \\
\text { Gilbert }\end{array}$ & 1935 & & \\
& $\begin{array}{c}\text { Wilma } \\
\text { Irma }\end{array}$ & 2005 & 160 & 82.31 \\
& $\begin{array}{c}\text { Mitch } \\
\text { Rita }\end{array}$ & 1998 & & \\
\hline
\end{tabular}

Table 5. List of intense hurricanes in terms of LMI that has been recorded in the produced LMI database.

\section{ATLANTIC SEA SURFACE TEMPERATURE}

The Atlantic SST data set from CMIP5 (World Climate Research Programme's Fifth Coupled Model Intercomparison Project) has been used for the analyses here. Such a data set includes four warming scenarios reports as Representative Concentration Pathways (RCPs), which provide historical records (1861-2005) and projection (by the end of the century) of SST values through several models for each scenario separately. These RCPs are specified by numbers $(2.6,4.5,6.0$ and 8.5$)$, which refer to the increase (in $\mathrm{W} / \mathrm{m}^{2}$ ) in radiative forcing (Meinshausen et al., 2011). RCPs are the same in the historical part and quite close to one another from 2005 to 2017. Hence, for the analyses in this 
study (1886-2017 in the ACR), the RCP2.6 has been selected. The SST values are downloaded from the KNMI (Royal Netherlands Meteorological Institute) Climate Explorer web application (https://climexp.knmi.nl/ plot_atlas_form.py). Each RCP warming scenario includes several models. However, they only have 24 models in common (Table 6).

\begin{tabular}{|l|l|l|l|}
\hline bcc-csm1-1 & GFDL-ESM2G & GISS-E2-R2 & Amon_MIROC5 \\
\hline CCSM4 & GFDL-ESM2M & GISS-E2-R3 & MIROC-ESM \\
\hline CESM1-CAM5 & GISS-E2-H1 & HadGEM2-AO & $\begin{array}{l}\text { MIROC-ESM- } \\
\text { CHEM }\end{array}$ \\
\hline CSIRO-Mk3-6-0 & GISS-E2-H2 & HadGEM2-ES & MRI-CGCM3 \\
\hline FIO-ESM & GISS-E2-H3 & IPSL-CM5A-LR & NorESM1-M \\
\hline GFDL-CM3 & GISS-E2-R1 & IPSL-CM5A-MR & NorESM1-ME \\
\hline
\end{tabular}

Table 6. List of 24 common models the four RCP scenarios.

For every year in the time series, an average of the 24 models of RCP2.6 is calculated and has been used for the analyses, see Figure 5. For the sake of simplicity in the following, this new multi-model mean of SST is called the Models Yearly Mean (MYM)

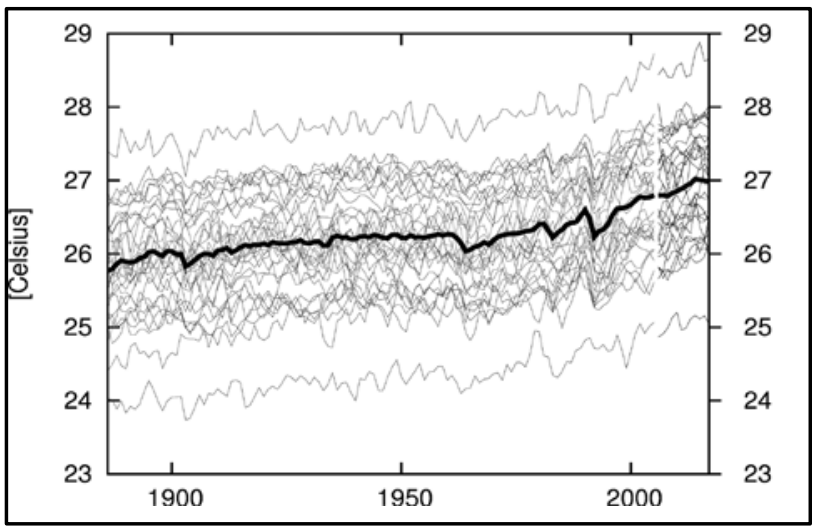

Figure 5. Atlantic SST in the ACR from 1886 to 2017 (JanuaryDecember). Thin lines represent the CMIP5 RCP2.6 models, and the Models Yearly Mean (MYM) is represented with a thick black line.

\section{CORRELATION BEWEEN YEARLY ATLANTIC HURRICANE FREQUENCIES AND MYM}

In order to estimate the influence of global warming on the Atlantic hurricane fequency, a Moving Window (MW) technique has been proposed. In the MW technique, a window with a fixed length moves from the beginning of the data set to the end with a one-year step forward, and for the last year at the end of the window in each step, the desired variables are computed by using the available data inside that window. The window continually moves one year forward, and the process repeats until the end of the period (last year of MW reaches the last year of the data set). The length of the MW should not be too short, so that it includes a statistically significant number of observations, and should not be too long so that changes occurring on relatively short time scales can be resolved. Our analyses indicate that the MW with a length equal to 30 years fulfills the abovementioned criteria. Consequently, having a 30-year moving window which continually moves a one-year step forward, starting from 1886 to 2017, we could compute 103 values in total for the desired variable, i.e., frequency of hurricanes.

The yearly number of events (produced in Sect. 4) inside a 30-year MW, with an intensity equal or higher than each SSHWS category, are considered as the observed frequencies of that category. For example, here the frequency of Category 1 refers to all the hurricanes in any category, and the frequency of Category 2 refers to all hurricanes, except those of Category 1. Observed frequencies are then averaged over the 30-year window. The MYM values are also averaged over the same window within which the frequencies are computed. Then the correlation between the averaged frequencies and the averaged MYM values corresponding to the same windows are calculated trough Least-Squares regression.

The correlation coefficients between each relationship are computed by measuring their linear dependence. In this regard, the Pearson correlation coefficient is used. Considering $\mathrm{X}$ as the MYM and Y as the frequency of different category of hurricanes:

$$
\rho(X, Y)=\frac{1}{N-1}\left(\frac{A_{i}-\mu_{X}}{\sigma_{X}}\right)\left(\frac{B_{i}-\mu_{Y}}{\sigma_{Y}}\right)
$$

where

$$
\begin{aligned}
\mu_{X} & =\text { mean of } \mathrm{X} \\
\sigma_{X} & =\text { standard deviation of } \mathrm{X} \\
\mu_{X} & =\text { mean of } \mathrm{Y} \\
\sigma_{Y} & =\text { standard deviation of } \mathrm{Y}
\end{aligned}
$$

The correlation coefficient could also be defined by means of the covariance:

$$
\rho(X, Y)=\frac{\operatorname{cov}(X, Y)}{\sigma_{X} \sigma_{Y}}
$$

Knowing the fact that the diagonal entries are equal to one, the correlation coefficient matrix of $\mathrm{X}$ and $\mathrm{Y}$ is:

$$
C=\left(\begin{array}{cc}
1 & \rho(X, Y) \\
\rho(X, Y) & 1
\end{array}\right)
$$

In the next step and for each relationship $(X, Y)$, a linear regression line is computed with the method of Least-Squares. If the model function has the form of $f\left(X_{i}, \beta\right)$ in which $m$ adjustable parameters are held in the vector $\beta$, the residuals $R$ are presented as:

$$
R_{i}=Y_{i}-f\left(X_{i}, \beta\right)
$$

Where data set consists of $n$ data pair of $\left(X_{i}, Y_{i}\right), i=1, \ldots, n$ and where $X_{i}$ is an independent variable and $Y_{i}$ is a dependent variable. Then the best fit in the Least-Squares sense is estimated by minimizing the sum of squared difference between an observed value, and the fitted value provided by a model, i.e., by minimizing the sum $S$ of squared residuals $v_{i}^{2}$.

$$
S=\sum_{i=1}^{n} v_{i}^{2}
$$

No weights have been included in the estimation process since all the observations have almost the same accuracy. Finally, the averaged observed frequencies are plotted versus the averaged MYM values corresponding to the same window and the LeastSquares lines are added to each graph (Fig. 6). 


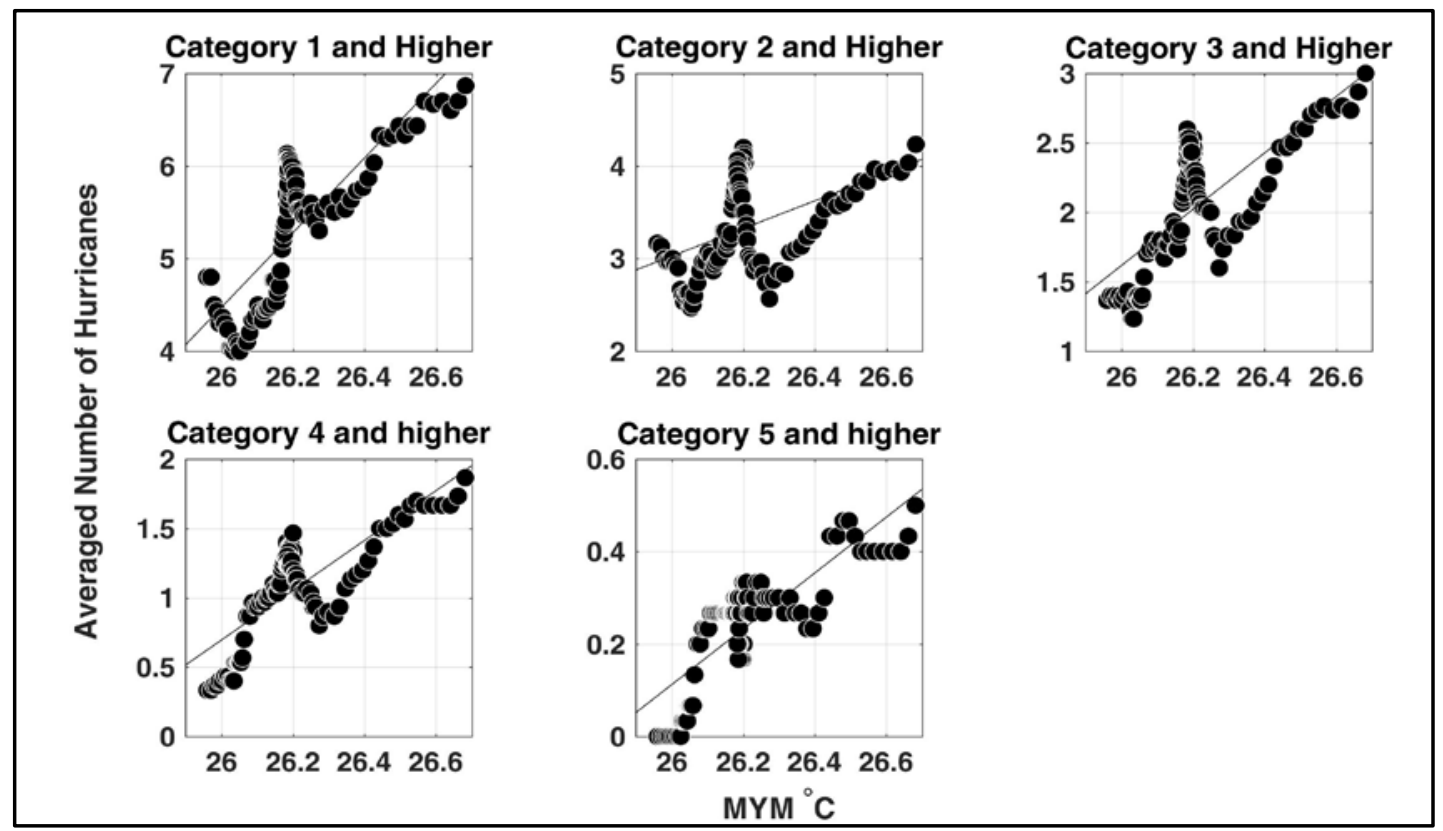

Figure 6. The relations between the averaged frequency of different SSHWS categories of hurricanes and averaged MYM values in the ACR from 1886 to 2017. The black lines are Least-Squares regression lines.

The computed correlation coefficients of relations between averaged MYM and averaged hurricane frequency for Category 1-5 are presented in Table 7. The highest correlation coefficient is for Category 5 intensity with $R=0.82$. It means that averaged MYM has a high correlation with the frequency of extreme hurricanes.

\begin{tabular}{|c|c|}
\hline Intensity & Correlation Coefficient \\
\hline Cat. 1 and higher & 0.81 \\
Cat. 2 and higher & 0.48 \\
Cat. 3 and higher & 0.74 \\
Cat. 4 and higher & 0.80 \\
Cat. 5 and higher & 0.82 \\
\hline
\end{tabular}

Table 7. Correlation coefficients of relations between averaged MYM and averaged hurricane frequencies, computed on different SSHWS categories.

\section{CONCLUSIONS}

In this study, the influence of climate change condition, mainly SST variations on the Atlantic hurricanes, has been examined. The analyses highlights and quantifies the influence of warming ocean on the frequency of hurricanes in the Atlantic tropical cyclogenesis regions from 1886 to 2017. It is found that the frequency of extreme hurricanes correlates very tightly with the Atlantic SST. More precisely the results indicate that the frequency of Category 5 hurricanes has a particularly high correlation with averaged MYM values over the same area.

In overall the results suggest that the hurricanes with an intensity equal or higher than Category 5 or in another word the extreme Atlantic hurricanes are more influenced from the increase in the temperature of the surface layer of Atlantic Ocean compared to the lower hurricane categories.
Future research will concern the estimate of probability prediction for different categories of hurricanes, and the extension of this methodology to investigate other regions. Beyond the effect of SST on hurricane formation, other effects which may influence this process will be considered, as for example the sea level rise (Tian et al., 2015).

\section{ACKNOWLEDGEMENTS}

This research has made use of the revised Atlantic hurricane database HURDAT2 from the National Hurricane Center (NHC).

\section{REFERENCES}

Bender, M. A., Knutson, T. R., Tuleya, R. E., Sirutis, J. J., Vecchi, G. A., Garner, S. T., and I. M. Held (2010). Modeled Impact of Anthropogenic Warming on the Frequency of Intense Atlantic Hurricanes. Science, 327(5964): 454-458, DOI: 10.1126/science.1180568

Bengtsson, L., Hodges, K. I., Esch, M., Keenlyside, N., Kornblueh, L., Luo, J. J., and T. Yamagata (2007). How may tropical cyclones change in a warmer climate? Tellus, Series A: Dynamic Meteorology and Oceanography, 59 A(4): 539-561, DOI: 10.1111/j.1600-0870.2007.00251.x

Chang, E. K. M., and Y. Guo (2007). Is the number of North Atlantic tropical cyclones significantly underestimated prior to the availability of satellite observations? Geophysical Research Letters, 34(14), paper No. L14801, DOI: 10.1029/2007GL030169

Dvorak, V. F. (1975). Tropical Cyclone Intensity Analysis and Forecasting from Satellite Imagery. Monthly Weather Review, 103(5): $\quad 420-430$, DOI: 10.1175/15200493(1975)103<0420:TCIAAF>2.0.CO;2 
Dvorak, V. F. (1984). Tropical Cyclone Intensity Analysis Using Satellite Data. NOAA Technical Report NESDIS 11.

Emanuel, K. A. (1991). The Theory Of Hurricanes. Annual Review of Fluid Mechanics, 23(1): 179-196, DOI: 10.1146/annurev.fluid.23.1.179

Emanuel, K. A. (2005). Increasing destructiveness of tropical cyclones over the past 30 years. Nature, 436(7051): 686-688, DOI: 10.1038/nature03906

Fraza, E., and J. B. Elsner (2015). A climatological study of the effect of sea-surface temperature on North Atlantic hurricane intensification. Physical Geography, 36(5): 395-407, DOI: 10.1080/02723646.2015.1066146

Goni, G. J., Black, P., and J., Trinanes (2002). Using satellite altimetry. NOAA Technical Report, (1), pp. 19-20.

Hagen, A. B., Strahan-Sakoskie, D., and C. Luckett (2012). A Reanalysis of the 1944-53 Atlantic Hurricane Seasons-The First Decade of Aircraft Reconnaissance. Journal of Climate, 25(13): 4441-4460, DOI: 10.1175/JCLI-D-11-00419.1

Holland, G. J. (1997). The Maximum Potential Intensity of Tropical Cyclones. Journal of the Atmospheric Sciences, 54(21): 2519-2541, DOI: 10.1175/1520-0469(1997)054<2519:TMPIOT $>2.0 . \mathrm{CO} ; 2$

Kanada, S., and others (2017). A Multimodel Intercomparison of an Intense Typhoon in Future, Warmer Climates by Four 5-kmMesh Models. Journal of Climate, 30(15): 6017-6036, DOI: 10.1175/JCLI-D-16-0715.1

Knutson, T. R., and others (2013). Dynamical Downscaling Projections of Twenty-First-Century Atlantic Hurricane Activity: CMIP3 and CMIP5 Model-Based Scenarios. Journal of Climate, 26(17): 6591-6617, DOI: 10.1175/JCLI-D-12-00539.1

Knutson, T. R., and others (2015). Global Projections of Intense Tropical Cyclone Activity for the Late Twenty-First Century from Dynamical Downscaling of CMIP5/RCP4.5 Scenarios. Journal of Climate, 28(18): 7203-7224, DOI: 10.1175/JCLI-D15-0129.1

Knutson, T. R., and R. E. Tuleya (2004). Impact of CO 2 Induced Warming on Simulated Hurricane Intensity and Precipitation: Sensitivity to the Choice of Climate Model and Convective Parameterization. Journal of Climate, 17(18): 34773495, DOI: 10.1175/1520-0442(2004)017<3477:IOCWOS> 2.0.CO;2

Landsea, C. W., and others (2012). A Reanalysis of the 1921-30 Atlantic Hurricane Database*. Journal of Climate, 25(3): 865885, DOI: 10.1175/JCLI-D-11-00026.1

Landsea, C. W., Franklin, J., and J. Beven (2015). The Revised Atlantic Hurricane Database (HURDAT2), (May), 1-6. Available at: http://www.nhc.noaa.gov/data/?text\#annual (last access on $31^{\text {th }}$ March 2018)

Landsea, C. W., and J. L. Franklin (2013). Atlantic Hurricane Database Uncertainty and Presentation of a New Database Format. Monthly Weather Review, 141(10): 3576-3592, DOI: 10.1175/MWR-D-12-00254.1

Landsea, C. W., and others (2008). A Reanalysis of the 1911-20
Atlantic Hurricane Database. Journal of Climate: 21(10), 21382168, DOI: 10.1175/2007JCLI1119.1

Landsea, C. W., and others (2014). A Reanalysis of the 1931-43 Atlantic Hurricane Database*. Journal of Climate: 27(16), 60936118, DOI: 10.1175/JCLI-D-13-00503.1

Mann, M. E., and K. A. Emanuel (2006). Atlantic hurricane trends linked to climate change. Eos, Transactions American Geophysical Union, 87(24), Paper No. 233, DOI: 10.1029/2006EO240001

Mann, M. E., Sabbatelli, T. A., and U. Neu (2007). Evidence for a modest undercount bias in early historical Atlantic tropical cyclone counts. Geophysical Research Letters, 34(22), paper No. L22707, DOI: 10.1029/2007GL031781

Meinshausen, M., and others (2011). The RCP greenhouse gas concentrations and their extensions from 1765 to 2300 . Climatic Change, 109(1-2): 213-241, DOI: 10.1007/s10584-011-0156-z

Santer, B. D., and others (2006). Forced and unforced ocean temperature changes in Atlantic and Pacific tropical cyclogenesis regions. Proceedings of the National Academy of Sciences, 103(38): 13905-13910, DOI: 10.1073/pnas.0602861103

Schott, T., and others (2012). The Saffir-Simpson Hurricane Wind Scale. National Hurricane Center, (February), 1-4. Available at: http://www.nhc.noaa.gov/pdf/sshws.pdf (last access on $31^{\text {th }}$ March 2018)

Sun, D., Kafatos, M., Cervone, G., Boybeyi, Z., and R. Yang (2007). Satellite microwave detected SST anomalies and hurricane intensification. Natural Hazards, 43(2): 273-284, DOI: $10.1007 / \mathrm{s} 11069-006-9099-5$

Tian, Y., Scaioni, M., Tong, X., and R. Li (2015). On the Conversion of Antarctic Ice-Mass Change to Sea Level Equivalent. Marine Geodesy, 38(1): 89-97, DOI: 10.1080/01490419.2014.969458

Torn, R. D., and C. Snyder (2012). Uncertainty of Tropical Cyclone Best-Track Information. Weather and Forecasting, 27(3): 715-729, DOI: 10.1175/WAF-D-11-00085.1

Vecchi, G. A., and T. R. Knutson (2008). On Estimates of Historical North Atlantic Tropical Cyclone Activity*. Journal of Climate, 21(14): 3580-3600, DOI: 10.1175/2008JCLI2178.1

Vecchi, G. A., and T. R. Knutson (2011). Estimating Annual Numbers of Atlantic Hurricanes Missing from the HURDAT Database (1878-1965) Using Ship Track Density. Journal of Climate, 24(6): 1736-1746, DOI: 10.1175/2010JCLI3810.1

Webster, P. J. (2005). Changes in Tropical Cyclone Number, Duration, and Intensity in a Warming Environment. Science, 309(5742): 1844-1846, DOI: 10.1126/science.1116448 